\title{
Effects of elective cesarean sections on perinatal outcomes and care practices
}

\author{
Anna Paula Ferrari 1 \\ (i) https://orcid.org/0000-0002-5370-4349 \\ Maiara Aparecida Mialich Almeida 2 \\ (iD) https://orcid.org/0000-0002-0641-0743 \\ Maria Antonieta Barros Leite Carvalhaes 3 \\ https://orcid.org/0000-0002-6695-0792 \\ Cristina Maria Garcia de Lima Parada 4 \\ https://orcid.org/0000-0002-9597-3635
}

\footnotetext{
1-4 Faculdade de Medicina. Universidade Estadual Paulista Júlio de Mesquita Filho. Campus Botucatu. Av. Prof. Mário Rubens Guimarães, s.n. Botucatu, SP, Brasil. CEP: 18.618-687. E-mail: gabi_anna@hotmail.com
}

\begin{abstract}
Objectives: to verify the effects of elective cesarean sections on perinatal outcomes and care practices, as compared to vaginal deliveries.

Methods: cohort study with 591 mothers and their babies, developed in a medium-sized city in the state of São Paulo, Brazil. Data were collected from hospital records and by interviews at the neonatal screening unit in the city from July 2015 to February 2016. Data regarding childbirth, newborns, sociodemography, and current gestational history were obtained from each mother. The associations of interest were evaluated with Cox regression analyses adjusted for the covariates identified through the results of bivariate analyses presenting a statistical significance level of $p<0.20$. In adjusted analyzes, relationships were considered significant if $p<0.05$, with relative risk being considered as the measure of effect.

Results: if compared to women who had vaginal deliveries, those who were submitted to elective cesarean sections were at a higher risk of not having skin-to-skin contact with their babies in the delivery room, of not breastfeeding in the first hour of life, and of having their babies hospitalized in a neonatal unit.

Conclusions: reducing the number of elective cesarean sections is essential to foster good neonatal care practices and reduce negative neonatal outcomes.
\end{abstract}

Key words Childbirth, Cesarean section, Elective surgical procedures, Morbidity, Newborns

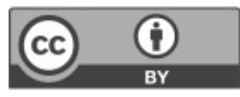




\section{Introduction}

Cesarean delivery has been very frequent for Brazilian women, especially among those with better socioeconomic conditions. This occurs even in situations where there is no maternal or fetal situation calling for such a procedure. As it is related to better financial conditions, the population, in general, has related this procedure to a supposed superior standard of care. ${ }^{1}$

Studies relating cesarean sections to an increased risk of maternal and child morbidity and mortality are found throughout the scientific literature. However, there is no proper discrimination between the outcomes related to indicated cesarean sections and elective cesarean sections.2,3

Considering cesarean sections in general, there is evidence of their association with adverse perinatal outcomes, such as the occurrence of prematurity, low birth weights, higher risk of needing a resuscitation, 5-minute Apgar scores of less than seven, delayed skin-to-skin contact, longer hospital stays, and a higher risk of hospitalization in Neonatal Intensive Care Units (ICU), Intermediate Care Units (IMCU) or Special Care Units, among others.4-8

Adverse perinatal outcomes often result from the gestational age when the option for an elective cesarean section occurs. According to the literature, elective cesarean sections taking place between 37 and 38 weeks of gestational age is a frequent practice. ${ }^{9}$ However, research shows that compared to those performed after the 39th week of pregnancy, they have more adverse perinatal results, such as an increased risk of death, respiratory disorders, hospitalization in a special unit and longer hospital stays. 10

There is still not enough evidence to point out the relationship of birth weight with elective cesarean sections. Studies carried out in different contexts have found no association between cesarean deliveries and low birth weight. ${ }^{11,12}$ However, some investigations have reported an association between cesarean deliveries and newborns with low birth weight. 13,14

Divergences in the literature have also been found regarding Apgar scores. A national study presented a result showing a decreasing trend in babies' vitality immediately after cesarean section births, ${ }^{4}$ while an international study revealed that babies born by cesarean section may have low vitality depending on the gestational age at which the surgical procedure takes place. 9

Regarding skin-to-skin contact, it is known that it should be stimulated from the first minutes of life due to the physiological and psychosocial benefits that this practice brings to the mother-baby binomial. ${ }^{15}$ However, babies born by cesarean section are less likely to have this moment respected: when indicated, most of the time, there is a need for immediate interventions for the establishment of extrauterine life and, when elective, there may be limitations for both mothers and newborns, hindering this process, which can lead to negative consequences for both. 5

Among other negative consequences related to cesarean sections, the late start of breastfeeding stands out. National and international studies have found similar results regarding this outcome: the likelihood of starting breastfeeding in the first hour of life is greater for babies born by vaginal delivery when compared to those born by cesarean section. Some of these studies distinguished between elective and indicated cesarean sections 16,17 and others did not. 5,18

As for the risk of hospitalization, a Brazilian study identified that the average length of time the newborn was hospitalized in cesarean deliveries was longer when compared to those born through vaginal deliveries. ${ }^{11}$ Furthermore, according to a global survey by the World Health Organization (WHO), the risk of hospitalization in neonatal Intensive Care Units (ICU) was higher for babies born by cesarean section. 19

This study is proposed considering the context of the current cesarean "epidemic" in many countries and the controversies regarding the perinatal results due to elective cesarean sections. The hypothesis that elective cesarean sections lead to negative effects will be tested separately on recommended neonatal care practices and the baby in the perinatal period and compared to the effects of vaginal deliveries. The objective is to verify the effect of elective cesarean sections, as compared to vaginal deliveries, on perinatal outcomes (gestational age at birth less than or equal to 38 weeks, birth weight less than 2,500g, 5-minute Apgar scores of less than seven, risk of admission to a Neonatal Intermediate Care Unit - NIMCU or Intensive Care Unit - ICU and length of stay) and care practices (absence of skin-to-skin contact in the delivery room and absence of breastfeeding in the first hour of life).

\section{Methods}

This study is a part of the CLaB survey (Botucatu Infant Cohort). $\mathrm{CLaB}$ followed a cohort of mothers and their newborns until they reached one year of age and, for most of the outcomes of interest (infant growth, infant morbidity, maternal weight retention, 
among others), it has a prospective design. However, for this article, where the relationship between being born by elective cesarean section (compared to vaginal births) and the risk of immediate postnatal outcomes was analyzed, the design is based on a historical cohort. The data related to the type of delivery, which allowed their classification into elective cesarean sections or vaginal deliveries (exposure variable), and the outcomes were collected from the medical records where the delivery took place and the chronology is known, as the delivery always precedes the outcomes relative to newborns and the medical records are filled out immediately after events occur.

The municipality of Botucatu is located in the south-central region of the state of São Paulo and had an estimated population of 144,820 in the year 2018.20 Concerning the city's primary care network for newborns, it has eight traditional basic care units and 12 family health units which have 15 teams and a neonatal screening unit, responsible for providing care to all children born in the municipality during their first month of life. 21

The cohort of the present study was composed of all the babies that were born in the two maternity hospitals (one public and one private) in the municipality from July 2015 to February 2016, as well as their mothers. Infants in the cohort underwent medical or nursing consultation at the neonatal screening unit were within the inclusion criteria of the research; their mothers were invited and agreed to participate in the study (totaling 650 mothers and 656 babies). The follow-up was completed in February 2017.

The only eligibility criterion adopted for the $\mathrm{CLaB}$ cohort was living in the urban area of the municipality of Botucatu. For the present study, binomials (newborns and their mothers) whose route of birth was classified as indicated cesarean section, twins, and those who did not complete follow-up were excluded. Therefore, the cohort studied was composed of 591 binomials, after the exclusion of six pairs of twins (12 babies), 43 infants born through indicated cesarean sections, and 10 binomials with incomplete data.

Births that did not meet any of the criteria for indicated cesarean delivery as set out by the National Commission for the Incorporation of Technologies for the Unified Health System (CONITEC Portuguese acronym) were classified as elective cesarean sections. These include the presence of a breach, placenta praevia, low-lying placenta or placenta accreta, HIV, iterativity, and genital herpes with active lesions. These criteria have been recom- mended by the Brazilian Ministry of Health since 2016.22

Data collection was carried out by a duly trained and supervised team made up of 19 people, including a nutrition student, a graduate nursing student, and technical training scholarship holders from the São Paulo Research Foundation (FAPESP). The interviewers were properly trained and supervised to guarantee the quality of data.

To answer the objectives of this study, data collected from the maternity records were used, complemented by data obtained through a face-toface interview with the mothers, carried out at the neonatal screening unit in the city. From the maternity records, data collected were related to childbirth, birth, and hospitalization period of the binomial. Through interviews, sociodemographic data, and maternal gestational history were obtained, as described in Table 1.

The instruments for data collection and recording were built by the researchers and tested in a pilot study to adjust questions that could present difficulties. To identify the family income per capita, the family's total income in Brazilian real was obtained and divided by the number of people dependent on this income. The classification was then carried out considering the value of the national minimum wage in January 2016.

The quality of the interviews was verified, via telephone, in a random sample of $5 \%$ of the participants through re-interviews conducted by field supervisors. Databases were checked, inconsistencies were verified in the questionnaires, and then corrections were made.

Initially, a bivariate analysis was performed between the type of delivery and the outcomes and covariables. Gross relative risks (RR) were estimated, with a 95\% confidence interval (CI95\%), using Cox regression models. The covariables that showed an association with a level of statistical significance of less than 0.20 were included in the multiple regression models due to their potential confounding effect in relation to the associations under investigation. The relationships between type of delivery and perinatal outcomes considered in this study were then assessed using multivariate Cox regression models. Relationships were considered significant if $p<0.05$, and the analyses were performed using the Statistical Package for the Social Sciences (SPSS) software, version 21.0.

Following national and international guidelines for research with human beings, this project was submitted to and approved by the Research Ethics Committee of the Botucatu College of Medicine 
Table 1

Study variables and data source regarding types of delivery and perinatal outcomes. Botucatu, 2017.

Variables

Data source

Independentvariables

- Types of delivery (vaginal delivery and elective cesarean section)

Medical Records

Outcomes

- Not having skin to skin contact at birth (yes / no)

Interview

- No breastfeeding in the first hour of life (yes / no)

Medical Records

- Gestational age at birth $\leq 38$ weeks (yes/no)

Medical Records

- Birth weight $<2,500 \mathrm{~g}$ (yes/no)

- Hospitalization in an Intensive Care Unit/Intermediate Care Unit (yes/no)

Medical Records

- 5-minute Apgar score of $<7$ (yes/no)

Medical Records

- Length of hospital stay (days)

Medical Records

Medical Records

Covariates

- Maternal age at delivery of $\leq 19$ years old (yes/no)

Interview

- Maternal schooling below eight years(yes/no)

Interview

- Family income per capita below one minimum wage (yes/no)

Interview

- Non-white maternal skin color (yes/no)

- Mother does not live with a partner (yes/no)

Interview

Interview

- Mother does not have paid work (yes/no)

Interview

- Unplanned pregnancy (yes/no)

Interview

- Childbirth not performed by the SUS (yes/no)

Interview

SUS= Sistema Único de Saúde (Unified Health System).

(CAAE: 37337314.3.0000.5411). The women who agreed to participate in the study signed the Free and Informed Consent Form.

\section{Results}

Of the total of 591 mother/infant binomials that comprised the analyzed cohort, $302(51.1 \%)$ had vaginal deliveries and $289(48.9 \%)$ were born via elective cesarean section.

Table 2 shows the sociodemographic and gestational characteristics of women and infant characteristics at birth according to the type of delivery. All of these variables, except ICU/IMCU admission, were selected to be later inserted as adjustment factors in the analyses between the type of delivery and the outcomes under study, as they differ according to the type of delivery at $p<0,20$.

Almost all babies who had no skin-to-skin contact were born by elective cesarean section $(93.1 \%)$ as well as $75.5 \%$ of those who did not breastfeed in their first hour of life. As for weight, $66.7 \%$ of babies born with less than $2,500 \mathrm{~g}$ were born via elective cesarean section and $33.3 \%$ via vaginal delivery. Regarding hospitalization, it is noteworthy that despite not being significantly associated with the type of delivery, $52.4 \%$ of babies who required ICU/IMCU admission were born via elective cesarean section. Elective cesarean sections were more common in women with better socioeconomic conditions and whose procedure was performed in a private hospital (Table 2).

The median total hospitalization time was two days for both types of delivery, ranging from zero to 34 days for those born vaginally and from zero to 43 days for those born via elective cesarean section $(p=0.795, \mathrm{RR}=0.99, \mathrm{CI} 95 \%=0.95-1.03)$. Among the four babies with a 5-minute Apgar score below seven, three were born via elective cesarean section, and one was delivered vaginally: $p=0.487$, $\mathrm{RR}=1.54$, CI95\% $=0.49-4.80$ (data not shown in table).

Tables 3 to 5 show the results of multiple Cox regressions between the type of delivery and perinatal care/outcome practices. Table 3 shows a significant association between the type of delivery and absence of skin-to-skin contact. Babies born by elective cesarean section, regardless of the potential confounders included in the analysis, have a higher risk (approximately 13 times) of not having skin-to- 
Sociodemographic characteristics of mothers, prenatal care, delivery, postpartum, and newborn according to the type of delivery (vaginal or elective cesarean section). Botucatu, 2015-2016.

\begin{tabular}{|c|c|c|c|c|c|c|}
\hline \multirow[t]{2}{*}{ Variables } & \multicolumn{2}{|c|}{ Vaginal delivery $(n=303)$} & \multicolumn{2}{|c|}{$\begin{array}{l}\text { Elective cesarean section } \\
\qquad(\mathrm{n}=289)\end{array}$} & \multirow[t]{2}{*}{$p^{*}$} & \multirow[t]{2}{*}{ RR (Cl95\%) } \\
\hline & $\mathrm{n}$ & $\%$ & $\mathrm{n}$ & $\%$ & & \\
\hline \multicolumn{7}{|l|}{ Age (years) } \\
\hline up to 19 & 58 & 63.0 & 34 & 37.0 & 0.076 & $0.72(0.50-1.03)$ \\
\hline$\geq 20$ & 245 & 49.0 & 255 & 51.0 & & 1 \\
\hline \multicolumn{7}{|c|}{ Maternal schooling (passed years) } \\
\hline Up to 7 & 37 & 69.8 & 16 & 30.2 & 0.043 & $0.59(0.36-0.98)$ \\
\hline$\geq 8$ & 266 & 49.4 & 273 & 50.6 & & 1 \\
\hline \multicolumn{7}{|l|}{ Skin Color } \\
\hline Non-white & 130 & 57.0 & 98 & 43.0 & 0.129 & $0.83(0.65-1.05)$ \\
\hline White & 173 & 47.5 & 191 & 52.5 & & 1 \\
\hline \multicolumn{7}{|c|}{ Mother lives with a partner } \\
\hline No & 47 & 65.3 & 25 & 34.7 & 0.080 & $0.69(0.46-1.04)$ \\
\hline Yes & 256 & 49.2 & 264 & 50.8 & & 1 \\
\hline \multicolumn{7}{|c|}{ Maternal paidwork } \\
\hline No & 158 & 62.7 & 94 & 37.3 & $<0.001$ & $0.65(0.50-0.83)$ \\
\hline Yes & 145 & 42.6 & 195 & 57.4 & & 1 \\
\hline \multicolumn{7}{|c|}{ Family income per capita (minimum wage) } \\
\hline Up to 1 & 264 & 62.6 & 158 & 37.4 & $<0.001$ & $0.49(0.39-0.63)$ \\
\hline$>1$ & 39 & 22.9 & 131 & 77.1 & & 1 \\
\hline \multicolumn{7}{|c|}{ Planned pregnancy } \\
\hline No & 179 & 57.6 & 132 & 42.4 & 0.021 & $0.76(0.60-0.96)$ \\
\hline Yes & 124 & 44.1 & 157 & 55.9 & & 1 \\
\hline \multicolumn{7}{|c|}{ Childbirth not performed by the SUS } \\
\hline Yes & 23 & 11.7 & 173 & 88.3 & $<0.001$ & $3.02(2.39-3.82)$ \\
\hline No & 280 & 70.7 & 116 & 29.3 & & 1 \\
\hline \multicolumn{7}{|c|}{ GA at infant's birth of $\leq 38$ weeks } \\
\hline Yes & 100 & 38.9 & 157 & 61.1 & $<0.001$ & $1.55(1.23-1.96)$ \\
\hline No & 203 & 60.6 & 132 & 39.4 & & 1 \\
\hline \multicolumn{7}{|c|}{ No skin to skin contact at birth } \\
\hline Yes & 13 & 6.9 & 176 & 93.1 & $<0.001$ & $3.31(2.62-4.19)$ \\
\hline No & 289 & 71.9 & 113 & 28.1 & & 1 \\
\hline \multicolumn{7}{|c|}{ No breastfeeding in the first hour of life } \\
\hline Yes & 50 & 24.5 & 154 & 75.5 & $<0.001$ & $2.16(1.72-2.72)$ \\
\hline No & 252 & 65.1 & 135 & 34.9 & & 1 \\
\hline \multicolumn{7}{|c|}{ Birth weight of less than $2,500 \mathrm{~g}$} \\
\hline Yes & 11 & 33.3 & 22 & 66.7 & 0.153 & $1.39(0.90-2.15)$ \\
\hline No & 291 & 52.2 & 267 & 47.9 & & 1 \\
\hline \multicolumn{7}{|c|}{ ICU/ICMU admission } \\
\hline Yes & 19 & 47.5 & 21 & 52.5 & 0.739 & $1.08(0.69-1.68)$ \\
\hline No & 283 & 51.4 & 268 & 48.6 & & 1 \\
\hline
\end{tabular}

* Result of bivariate Cox regression; RR = relative risk; CI95\% = 95\% confidence interval; GA = gestational age; ICU = Intensive Care Unit/Intermediate Care Unit; SUS= Sistema Único de Saúde (Unified Health System).

skin contact as soon as they are born. Also independently, babies born via elective cesarean section are at greater risk (approximately twice as high) of not being breastfed in the first hour of life when compared to those born via vaginal delivery (Table
4). The need for admission to an ICU/IMCU was also assessed. It was found that the risk increases approximately two times for those born by elective cesarean section (Table 5 ); $65 \%$ of the children who needed to be hospitalized in these units presented 
changes in their respiratory pattern (data not shown in table).

Multivariate regression analyzes performed for the following outcomes were not associated with the type of delivery: gestational age of less than or equal to 38 weeks at birth, birth weight of less than 2,500 g, and 5-minute Apgar scores of less than seven. Although babies born by elective cesarean section have longer hospital stays when compared to those born via vaginal delivery, this result did not have clinical significance since the longest period of hospitalization was only half a day (data not shown in table).

Table 3

Result of multiple Cox regression investigating the association between type of delivery and not having skin to skin contact in the delivery room. Botucatu, 2015-2016.

\begin{tabular}{lccc}
\hline Variable & RR & Cl95\% & p \\
\hline Maternal age of 19 years old or less & 1.29 & $0.83-2.01$ & 0.258 \\
Non-white skin color & 0.94 & 0.734 \\
Mother does not live with partner & 0.82 & $0.46-1.44$ & 0.497 \\
Mother does not perform paid work & 0.92 & $0.65-1.31$ & 0.665 \\
Maternal education of less than 8 years & 1.10 & $0.60-2.02$ & 0.762 \\
Family income per capita of less than one minimum wage & 0.91 & $0.63-1.30$ & 0.607 \\
Unplanned pregnancy & 1.07 & $0.79-1.45$ & 0.647 \\
Childbirth not performed by the SUS & 1.01 & $0.69-1.50$ & $0.71-1.37$ \\
Gestational age of the infant at birth of $\leq 38$ weeks & 0.99 & 1.631 \\
Elective cesarean section & & 0.960 & $<.74$ \\
\hline
\end{tabular}

$\mathrm{RR}=$ relative risk; $\mathrm{C} 195 \%=95 \%$ confidence interval; SUS= Sistema Único de Saúde (Unified Health System).

\section{Table 4}

Result of multiple Cox regression investigating the association between type of delivery and lack of breastfeeding in the first hour of life. Botucatu, 2015-2016.

\begin{tabular}{lccc}
\hline Variable & RR & Cl95\% & $\boldsymbol{p}$ \\
\hline Maternal age of 19 years old or less & 1.02 & $0.65-1.60$ & 0.914 \\
Non-white skin color & 0.95 & $0.69-1.29$ & 0.743 \\
Mother does not live with partner & 1.14 & $0.69-1.87$ & 0.598 \\
Mother does not perform paid work & 1.04 & $0.74-1.45$ & 0.828 \\
Maternal education of less than 8 years & 0.97 & $0.53-1.78$ & 0.930 \\
Family income per capita of less than one minimum wage & 0.89 & $0.63-1.26$ & 0.524 \\
Unplanned pregnancy & 0.97 & $1.03-2.30$ & 0.034 \\
Childbirth not performed by the SUS & 1.54 & 1.34 & $0.98-1.82$ \\
Gestational age of the infant at birth of $\leq 38$ weeks & 2.29 & $1.56-3.34$ \\
Elective cesarean section & & 0.067 \\
\hline
\end{tabular}

$\mathrm{RR}=$ relative risk; $\mathrm{Cl} 95 \%=95 \%$ confidence interval; SUS= Sistema Único de Saúde (Unified Health System). 
Result of Cox regression investigating the association between type of delivery and need for ICU admission. Botucatu, 2015-2016.

\begin{tabular}{|c|c|c|c|}
\hline Variable & $\mathbf{R} \mathbf{R}$ & $\mathrm{Cl} 95 \%$ & $p$ \\
\hline Maternal age of 19 years old or less & 1.11 & $0.49-2.50$ & 0.802 \\
\hline Non-white skin color & 1.05 & $0.55-1.99$ & 0.879 \\
\hline Mother does not live with partner & 1.85 & $0.88-3.88$ & 0.105 \\
\hline Mother does not perform paid work & 0.71 & $0.36-1.40$ & 0.328 \\
\hline Maternal education of less than 8 years & 2.12 & $0.97-4.60$ & 0.058 \\
\hline Family income per capita of less than one minimum wage & 0.63 & $0.23-1.71$ & 0.371 \\
\hline Unplanned pregnancy & 1.42 & $0.72-3.02$ & 0.285 \\
\hline Childbirth not performed by the SUS & 0.11 & $0.03-0.37$ & $<0.001$ \\
\hline Gestational age of the infant at birth of $\leq 38$ weeks & 1.85 & $0.97-3.52$ & 0.061 \\
\hline Elective cesarean section & 2.26 & $1.18-4.35$ & 0.014 \\
\hline
\end{tabular}

ICU = Intensive Care Unit; IMCU = Intermediate Care Unit; RR = relative risk; $C 195 \%=95 \%$ confidence interval; SUS=Sistema Único de Saúde (Unified Health System).

\section{Discussion}

This study allowed for the identification of adverse perinatal outcomes associated with elective cesarean section in a historical cohort studied in a municipality in the state of São Paulo. Negative effects of elective cesarean sections with clinical significance included a lack of skin-to-skin contact and breastfeeding in the first hour of life and a higher risk of admission to an ICU/IMCU.

Babies born via elective cesarean section in the context under study had 13 times more risk of not experiencing skin-to-skin contact with their mothers at birth. This fact deprives them of the countless benefits of this neonatal care practice. The BabyFriendly Hospital Initiative (BFHI), launched in 1990 and revised in 2018, presents, in its fourth step, the importance of promoting uninterrupted skin-toskin contact immediately after delivery. ${ }^{23}$ This practice is closely related to the success of breastfeeding because when the mother touches the newborn, this leads to a hormonal discharge that favors lactation. Furthermore, it has a positive effect on the blood glucose levels and the cardiorespiratory stability of the newborn. In the medium and long term, it also positively influences the maintenance of the motherchild bond and the duration of breastfeeding. ${ }^{24}$

Despite its proven benefits, safety, and the fact that the procedure does not require any financial resources, skin-to-skin contact is still a neglected practice in Brazil.24 Data in the present study corroborate this statement since $65.8 \%$ of babies did not have skin-to-skin contact with their mothers after birth and having an elective cesarean section increased the chances of this outcome.

It was not possible to locate studies on the effects of elective cesarean sections for comparison with the present study, but the scientific literature on cesarean deliveries in general shows similar results: data from a Brazilian survey shows that babies born via cesarean section are significantly more likely to be removed from their mothers at birth when compared to those born through a vaginaldelivery25; a study carried out in a hospital accredited in the Amigo da Criança (Children's Friend) program in the south of the state of Paraná, whose objective was to analyze factors involved in the practice of skin-to-skin contact, points to cesarean section as one of the main obstacles to the practice. 26

Breastfeeding in the first hour of life, the success of which is closely related to skin-to-skin contact, was also more frequent for babies born via vaginal delivery. Among the babies who were breastfed in their first hour of life, $65.2 \%$ were born vaginally while $34.8 \%$ were born by elective cesarean section. The risk of not breastfeeding in the first hour was twice as high for those born via elective cesarean section compared to those born by vaginal delivery.

Breastfeeding in the first hour of life provides a protective effect on neonatal mortality. A study developed by researchers from the University of Rio de Janeiro in partnership with Yale University, with secondary data from 67 countries, showed that the lowest breastfeeding tertiles in the first hour of life presented a rate of infant mortality $24 \%$ higher than other babies. 27

The evidence presents data that corroborates the results of this investigation on breastfeeding in the first hour of life. A cross-sectional study carried out in maternity hospitals in Rio de Janeiro shows that breastfeeding at that time was less prevalent among babies born by cesarean section. 28 A systematic 
review suggests that cesarean section is the most consistent risk factor for lack of breastfeeding in the first hour of life. 29

In this sense, it can be said that babies born by elective cesarean section are less exposed to skin-toskin contact with their mothers, which results in an increased risk for not breastfeeding in the first hour of life and, consequently, increases the risk of adverse events due to the non-implementation of these two practices, such as non-cardiorespiratory stabilization at birth, neonatal death and early weaning or difficulties in the breastfeeding process.

Another outcome associated with elective cesarean sections was the need for admission to the ICU/IMCU. The risk of this type of hospitalization was approximately twice as high for babies born by elective cesarean section when compared to those born via vaginal delivery.

Again, similar studies were not found for comparison, but delivering via cesarean section has already been identified in the literature as a risk factor for neonatal hospitalization in special care units. An Australian study with information collected from the country's national perinatal database aimed to determine the admission rate of full-term babies into neonatal ICUs and to measure its associations to different types of delivery and found that the chance of women at low gestational risk having their newborns admitted to the ICU was greater when they underwent cesarean sections, and even greater when the cesarean section took place before the onset of labor. 30

Considering that changes in breathing pattern were the main cause of hospitalization in an ICU/IMCU identified in this study and the majority of hospitalizations were of babies born by elective cesarean section, it can be assumed that the fact that the baby does not pass through the birth canal has caused pulmonary expansion damage, leading to a need for special care to carry out respiratory adaptation.

Contradicting one of this study's hypotheses, there was no negative effect of elective cesarean sections on gestational age at birth less than or equal to 38 weeks, birth weight lower than $2,500 \mathrm{~g}$, and 5minute Apgar scores of less than seven in the multivariate analysis. Due to this, it can be assumed that, in general, elective cesarean sections were performed at an appropriate time in the context under study, which prevented the occurrence of prematurity and/or inadequate weight or physiological conditions of the baby at birth.

Originality stands out as a strong point of this study since it distinguishes indicated cesareans from elective cesareans, a differentiation that rarely happens in the literature. Another positive aspect is the sample's representativeness in regards to the composition of the population since cohort recruitment took place in services with high population coverage, including both the population that uses the SUS and those that have access to private medical insurance. As a limitation, we highlight the fact that part of the data, especially those used to define the type of cesarean section (elective or indicated), was collected from a secondary source (medical records from both maternity hospitals in the municipality). To reduce the risk of having indicated cesarean sections categorized as being elective, it was decided to consider cesarean sections as being indicated in the absence of data.

Taken together, the results obtained suggest that reducing the high rates of elective cesarean sections would increase the frequency of newborns being exposed to good neonatal care practices as well as reducing the occurrence of adverse neonatal outcomes. They also support the widespread disclosure of the increased risks of negative outcomes resulting from elective cesarean sections, clearly pointing out that these are independent of the woman's socioeconomic level and the childbirth care provider.

It is concluded that, among the studied outcomes, the effect of elective cesarean section is negative for important neonatal care practices (skinto-skin contact and breastfeeding in the first hour of life) and for the risk of needing intensive or intermediate care.

Reducing the rate of elective cesarean sections is essential for an increase in good practices aimed at neonatal care and a consequent drop in adverse neonatal outcomes.

New studies that explore other associations between elective cesarean sections and outcomes at birth may highlight relevant aspects that public managers should focus on to develop interventions capable of reducing the prevalence of this type of delivery and improving neonatal outcomes, both in the public and private health sectors.

\section{Authors' contribution}

Ferrari AP worked on the design of the research project, data collection, data interpretation, and writing of the article. Almeida MAM worked on data collection, critical review of the article. Carvalhaes MABL worked on data analysis and critical review. Parada CMGL worked on the study design, data analysis and article preparation. All authors approved the final version of the article. 


\section{References}

1. Domingues RMSM, Dias MAB, Nakamura-Pereira $M$, Torres JA, d'Orsi E, Pereira APE, Schilithz AOC, do Carmol Leal M. Processo de decisão pelo tipo de parto no Brasil: da preferência inicial das mulheres à via de parto final. Cad Saúde Pública. 2014; 30 (Suppl. 1):S101-16.

2. Leguizamon Junior T, Steffani JA, Bonamigo EL. Escolha da via de parto: expectativa de gestantes e obstetras. Rev Bioética. 2013; 21 (3): 509-17.

3. Torres JA, Domingues RMSM, Sandall J, Hartz Z, Gama SGN, Filha MMT, Schilitz AOC, do Carmo Leal M. Cesariana e resultados neonatais em hospitais privados no Brasil: estudo comparativo de dois diferentes modelos de atenção perinatal. Cad Saúde Pública. 2014; 30 (Suppl. 1): S220-31.

4. Franceschini DTB, Cunha MLC. Associação da vitalidade do recém-nascido com o tipo de parto. Rev Gauch Enferm. 2007; 28 (3):324-30

5. Belo MNM, Azevedo PTÁCC, Belo MPM, Serva VMSBD, Batista Filho M, Figueiroa JN, Caminha MFC. Aleitamento materno na primeira hora de vida em um Hospital Amigo da Criança: prevalência, fatores associados e razões para sua não ocorrência. Rev Bras Saúde Matern Infant. 2014; 14 (1): $65-72$

6. Ferrari APF, Carvalhaes MABL, Parada CMGL Associação entre pré-natal e parto na rede de saúde suplementar e cesárea eletiva. Rev Bras Epidemiol. 2016; 19 (1): 75-88.

7. Oliveira LL, Gonçalves AC, Costa JSD, Bonilha ALL. Maternal and neonatal factors related to prematurity. Rev Esc Enferm USP. 2016; 50 (3): 382-9

8. Demestre Guasch X, García Reymundo M, Hurtado Suazo JA, Calvo Aguilar MJ, Ginovart Galiana G, Jiménez Moya A. Prematuridad tardía: una población de riesgo. Clin Invest Ginecol Obstet. 2018; 45 (1):17-23.

9. Wilmink FA, Hukkelhoven CWPM, Lunshof S, Mol BWJ, van der Post JAM, Papatsonis DNM. Neonatal outcome following elective cesarean section beyond 37 weeks of gestation: a 7-year retrospective analysis of a national registry. Am J Obstet Gynecol. 2010; 202 (3): 250.e1250.e8.

10. Phaloprakarn C, Tangjitgamol S, Manusirivithaya S. Timing of elective cesarean delivery at term and its impact on maternal and neonatal outcomes among Thai and other Southeast Asian pregnant women. J Obstet Gynaecol Res. 2016; 42 (8): 936-43.

11. Cardoso PO, Alberti LR, Petroianu A. Morbidade neonatal e maternas relacionada ao tipo de parto. Ciên Saúde Coletiva. 2010;15 (2):427-35.

12. Reis ZSN, Lage EM, Aguiar RALP, Gaspar JS, Vitral GLN, Machado EG. Associacao entre risco gestacional e tipo de parto com as repercussoes maternas e neonatais. Rev Bras Ginecol Obstet. 2014;36(2):65-71.

13. Chen C, Yan Y, Gao X, Xiang S, He Q, Zeng G, Liu S, Sha T, Li L. Effects of cesarean delivery on breastfeeding practices and duration: a prospective cohort study. J Hum Lact. 2018;34(3):526-34. 14 Moraes AB, Zanini RR, Giugliani ERJ, Riboldi J. Tendência da proporção de baixo peso ao nascer, no período de 1994-2004, por microrregião do Rio Grande do Sul, Brasil: uma análise multinível. Cad Saúde Pública. 2011; 27 (2): 229-40.

15. Matos TA, Souza MS, Santos EKA, Velho MB, Seibert ERC, Martins NM. Contato precoce pele a pele entre mãe e filho: significado para mães e contribuições para a enfermagem. Rev Bras Enferm. 2010; 63 (6): 998-1004.

16. Prior E, Santhakumaran S, Gale C, Philipps L, Modi N, Hyde M. Breastfeeding after cesarean delivery: a systematic review and meta-analysis of world literature. Am J Clin Nutr. 2012; 95 (5): 1113-35

17. Hobbs AJ, Mannion CA, McDonald SW, Brockway M, Tough SC. The impact of caesarean section on breastfeeding initiation, duration and difficulties in the first four months postpartum. BMC Pregnancy Childbirth. 2016; 16 (1): 90

18. Berde AS, Yalcin SS. Determinants of early initiation of breastfeeding in Nigeria: a population-based study using the 2013 demograhic and health survey data. BMC Pregnancy Childbirth. 2016; 16 (1):32

19. Lumbiganon P, Laopaiboon M, Gülmezoglu AM, Souza JP, Taneepanichskul S, Ruyan P, Attygalle DE, Shrestha N, Mori R, Nguyen DH, Hoang TB, Rathavy T, Chuyun K, Cheang K, Festin M, Udomprasertgul V, Germar MJ, Yanqiu G, Roy M, Carroli G, Ba-Thike K, Filatova E, Villar $\mathrm{J}$. Method of delivery and pregnancy outcomes in Asia: the WHO global survey on maternal and perinatal health 2007-08. Lancet. 2010; 375 (9713): 490-9.

20. IBGE (Instituto Brasileiro de Geografia e Estatística). Cidades. Brasília, DF; 2018 [acesso 12 Jun 2018]. Disponível em: https://cidades.ibge.gov.br/brasil/sp/botucatu/panorama

21. Prefeitura Municipal de Botucatu - Secretaria Municipal de Saúde. Manual de Procedimento Operacional Padrão: Clínica do Bebê. Botucatu; 2012.

22. CONITEC. Comissão Nacional de Incorporação de Tecnologias no SUS. Diretrizes de atenção à gestante: a operação cesariana: Brasília, DF: Ministério da Saúde; 2016. p. 1-115. (Protocolo; 179).

23. WHO (World Health Organization). Ten steps to successful breastfeeding (revised 2018) [Internet]. 2018 [acesso 20 Jan 2020]. Disponível em: https://www.who.int/nutrition/bfhi/ten-steps/en/

24. Sampaio ÁRR, Bousquat A, Barros C. Contato pele a pele ao nascer: um desafio para a promoção do aleitamento materno em maternidade pública no Nordeste brasileiro com o título de Hospital Amigo da Criança. Epidemiol Serv Saúde. $2016 ; 25$ (2): 1-2.

25. Moreira MEL, Gama SGN, Pereira APE, Silva AAM, Lansky S, Pinheiro RS, Gonçalves AC, Carmo Leal M. Práticas de atenção hospitalar ao recém-nascido saudável no Brasil. Cad Saúde Pública. 2014;30 (Suppl. 1): S128-39.

26. D'Artibale EF, Bercini LO. The practice of the fourth step of the baby friendly hospital initiative. Esc Anna Nery Rev Enferm. 2014; 18 (2): 356-64

27. Boccolini CS, Carvalho ML, Oliveira MIC, PérezEscamilla R. Breastfeeding during the first hour of life and 
neonatal mortality. J Pediatr (Rio J). 2013; 89 (2): 131-6.

28. Boccolini CS, Carvalho ML, Oliveira MIC, Vasconcellos AGG. Fatores associados à amamentação na primeira hora de vida. Rev Saúde Pública. 2011; 45 (1): 69-78.

29. Esteves TMB, Daumas RP, Oliveira MIC, Andrade CAF, Leite IC. Factors associated to breastfeeding in the first hour of life: systematic review. Rev Saúde Pública. 2014; 48 (4): 697-708.
30. Tracy SK, Sullivan EA, Tracy MB. Admission of term infants to neonatal intensive care: A population based study. Birth Issues Perinat Care. 2007; 34: 301-8.

Received on May 13, 2019

Final version presented on April 26, 2020

Approved on May 26, 2020 